\title{
Percutaneous Intervention of a Persistent Left Superior Vena Cava Draining Into Left Pulmonary Vein and Coarctation of the Aorta
}

\author{
Saad Al Bugami ${ }^{\mathrm{a}, \mathrm{e}}$, Mohammed Althobaiti ${ }^{\mathrm{b}}$, Tarek Momenah ${ }^{\mathrm{c}}$, Jamilah Alrahimi ${ }^{\mathrm{a}}$, \\ Wael Al Kashkari ${ }^{\mathrm{d}}$
}

\begin{abstract}
We describe a 54-year-old male with history of type II DM, hypertension and dyslipidemia during admission for bronchopneumonia discovered to have coarctation of the aorta and a persistent left superior vena cava (PLSVC) draining into the left atrium through the left superior pulmonary vein. The latter was thought to contribute to a transient ischemic attack and an episode of chest pain resulting in ST-segment elevation in the inferior leads. He was treated with coarctation stenting and percutaneous exclusion of the PLSVC with a vascular plug.
\end{abstract}

Keywords: Percutaneous intervention; Coarctation of the aorta; Persistent left superior vena cava; Amplatzer vascular plug II

\section{Introduction}

Persistent left superior vena cava (PLSVC) is a relatively common anatomical variant, with an incidence of $0.3 \%$ in autopsy studies [1]. In patients with congenital heart defects, a PLSVC is seen in up to $10 \%$ of patients; additional cardiac defects include atrial septal defect, bicuspid aortic valve, coarctation of aorta, coronary sinus ostial atresia, cortriatriatum, tetralogy of Fallot, and heterotaxy syndrome [1-4]. The PLSVC usually drains into the right atrium via the coronary sinus. In the rare case of coronary sinus ostial atresia, the LSVC drains the coronary venous blood flow from the coronary sinus to the

Manuscript accepted for publication July 21, 2016

aking Saud bin Abdulaziz University for Health Sciences; King Faisal Cardiac Center, King Saud bin Abdulaziz Medical City, Jeddah, Saudi Arabia

${ }^{b}$ King Saud bin Abdulaziz University for Health Sciences; King Abdulaziz Medical City, Jeddah, Saudi Arabia

cPrince Sultan Cardiac Center, Riyadh, Saudi Arabia

dKing Faisal Cardiac Center, King Saud bin Abdulaziz Medical City, Jeddah, Saudi Arabia

eCorresponding Author: Saad Al Bugami, King Saud bin Abdulaziz University, King Abdulaziz Medical City, king Faisal Cardiac Center, Jeddah 21423, Saudi Arabia. Email: bogamisa@ngha.med.sa

doi: http://dx.doi.org/10.14740/cr477w systemic venous circulation. These anomalies cause no shunts [5-9]. However, in 10-20\% of cases, it drains to the left atrium either via unroofed coronary sinus, or in a straight line fashion into the roof of the left atrium, or the left superior pulmonary vein [10]. It is in this kind of abnormal connection where there is shunting and occlusion is required [11]. We describe a case of combined coarctation of the aorta and PSLVC draining into the left pulmonary vein treated percutaneously.

\section{Case Report}

A 54-year-old male patient with long standing history of type II DM, dyslipidemia and hypertension, with medical therapy of bisoprolol $10 \mathrm{mg}$ daily, valsartan $160 \mathrm{mg}$ daily, HCTZ $25 \mathrm{mg}$ daily, atorvastatin $20 \mathrm{mg}$ nocturnally, insulin and metformin was admitted to a peripheral hospital with bronchopneumonia requiring high dependency unit admission. This was complicated by a transient ischemic attack. Brain computed tomography $(\mathrm{CT})$ was normal. On the second day of admission, he had a significant episode of chest pain. Electrocardiogram (ECG) showed transient ST-segment elevation with spontaneous resolution in the inferior lead. There was mild troponin leak. He was later referred to our center for further workup. His physical exam revealed oxygen saturation at $98 \%$ on room air, pulse $70 \mathrm{bpm}$, BP both upper limb 155/65 mm Hg, and BP lower limb 105/45 mm Hg. There was a brachio-femoral delay. Apex was mildly displaced; he had $\mathrm{S} 1+\mathrm{S} 2+\mathrm{S} 4$ and a systolic murmur at the tip of left scapula; no clicks were appreciated on auscultation.

ECG showed sinus rhythm and left ventricular hypertrophy (LVH) with strain pattern. A 24-h Holter came back with normal sinus rhythm, no atrial fibrillation, no heart blocks or arrhythmia. Transthoracic echocardiogram revealed concentric $\mathrm{LVH}$, borderline left ventricular function of $45-50 \%$, mild to moderate aortic regurgitation, bicuspid aortic valve and a coarctation of the aorta with a $70 \mathrm{~mm} \mathrm{Hg}$ gradient across it. Brain MRI demonstrated lacunar infarcts and no AV-malformations. Both carotid arteries were free of atherosclerosis on Doppler. Coronary CT angiogram not only demonstrated the tight coarctation but also showed a rare anomaly of a PLSVC draining into the left atrium (Fig. 1). Anomalous pulmonary drainage and pulmonary arteriovenous malformation were excluded. The approach to management of this patient was discussed in a 


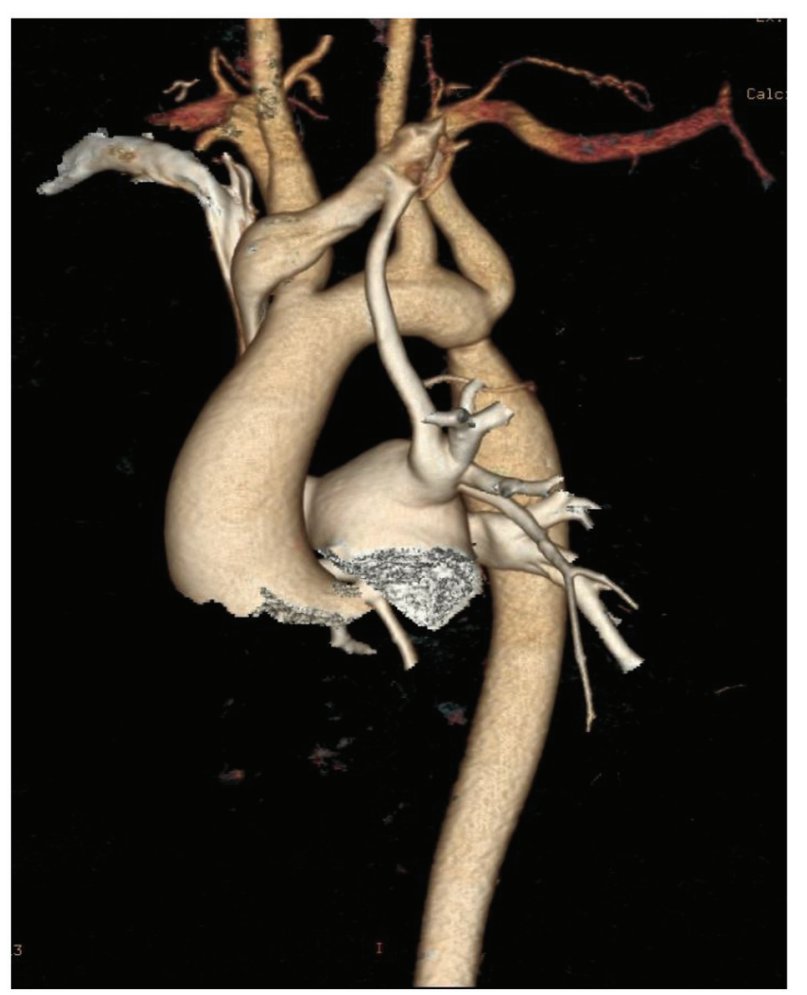

Figure 1. Volume rendered 3D image demonstrating the PLSVC draining into the left superior pulmonary vein then into the left atrium and the tight coarctation.

heart team meeting. It was decided to proceed percutaneously.

The patient was brought to the catheterization laboratory. Coronary angiography showed normal coronaries. He did have a significant coarctation with a pressure gradient of $40 \mathrm{~mm} \mathrm{Hg}$. Angiographic confirmation of the PLSVC draining into the left superior pulmonary vein was confirmed. A $40 \mathrm{~mm} \mathrm{CP}$ stent mounted on a $20 \times 45 \mathrm{~mm}$ BIB balloon was deployed successfully (Fig. 2), guided by fluoroscopy and overdrive pacing. There was complete abolition of the gradient. At a later

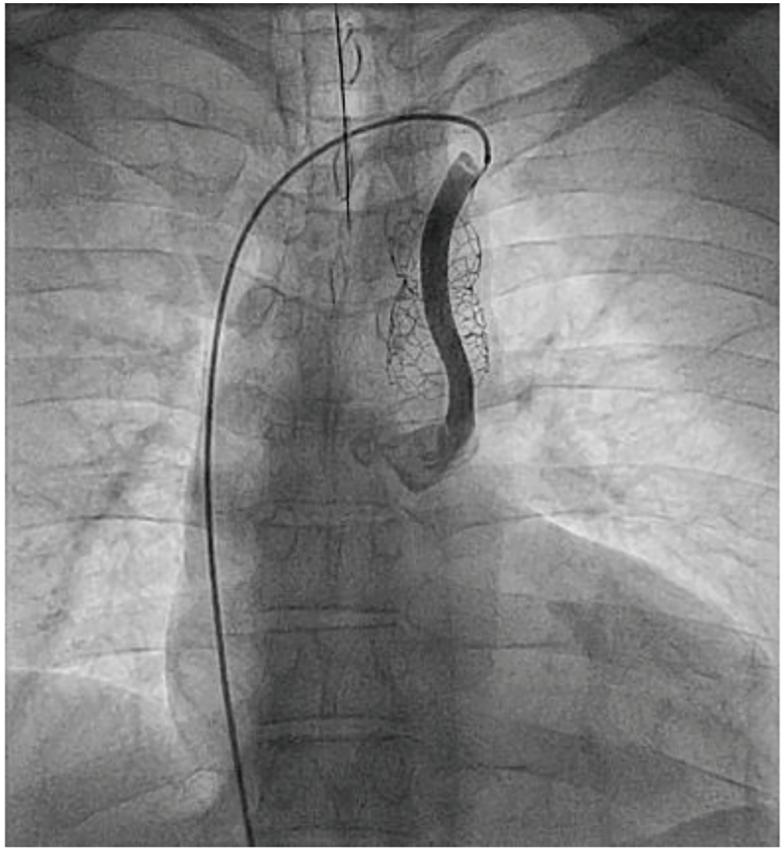

Figure 3. The PLSVC draining into the left superior pulmonary vein then into the left atrium.

date, the patient was brought for PLSVC exclusion therapy. Selective angiography of the PLSVC was performed to delineate vessel course and venous drainage (Fig. 3). Using a marker pigtail measurement of the vessel was obtained. The PLSVC measured $9 \mathrm{~mm}$ proximally, $10.5 \mathrm{~mm}$ at its mid-point and $8 \mathrm{~mm}$ near the entrance to the left upper pulmonary vein. The PLSVC was then temporarily occluded with an $8 \mathrm{~mm}$ peripheral balloon to make sure that the patient would tolerate closure of the vessel. There was no significant change in the patient's hemodynamic measurements, and the decision was made to proceed with transcatheter occlusion of the PLSVC which was achieved using a $12 \mathrm{~mm}$ Amplatzer vascular plug II (AGA Medical Corporation, Golden Valley, MN) (Fig. 4).

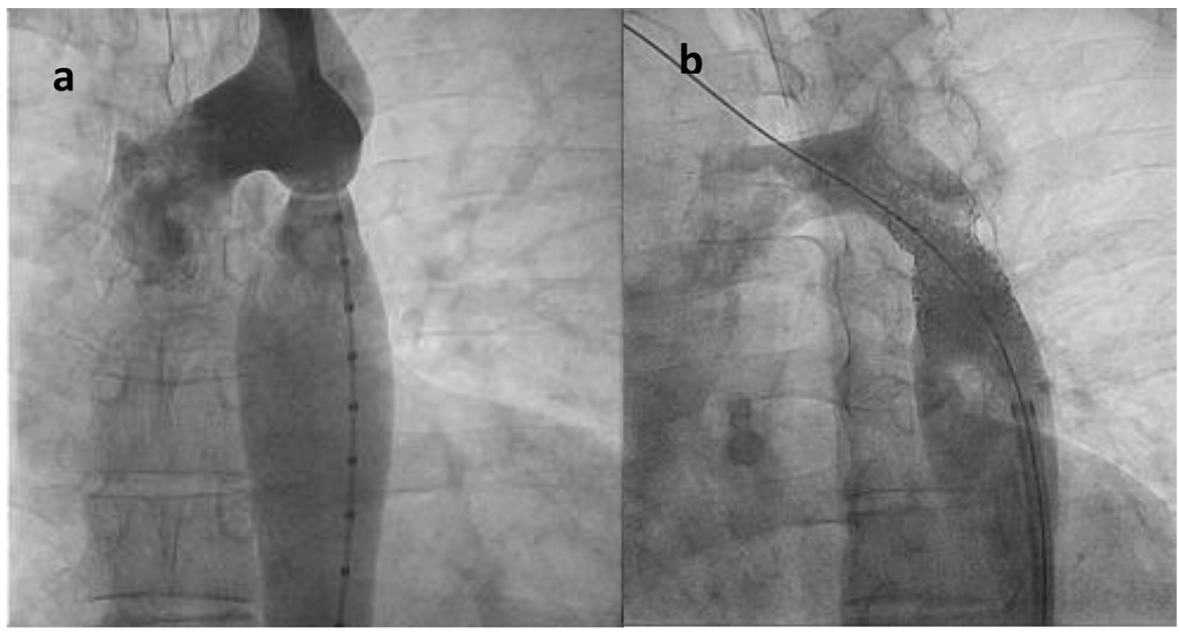

Figure 2. (a) Pre-coarctation and (b) post-coarctation stenting. 

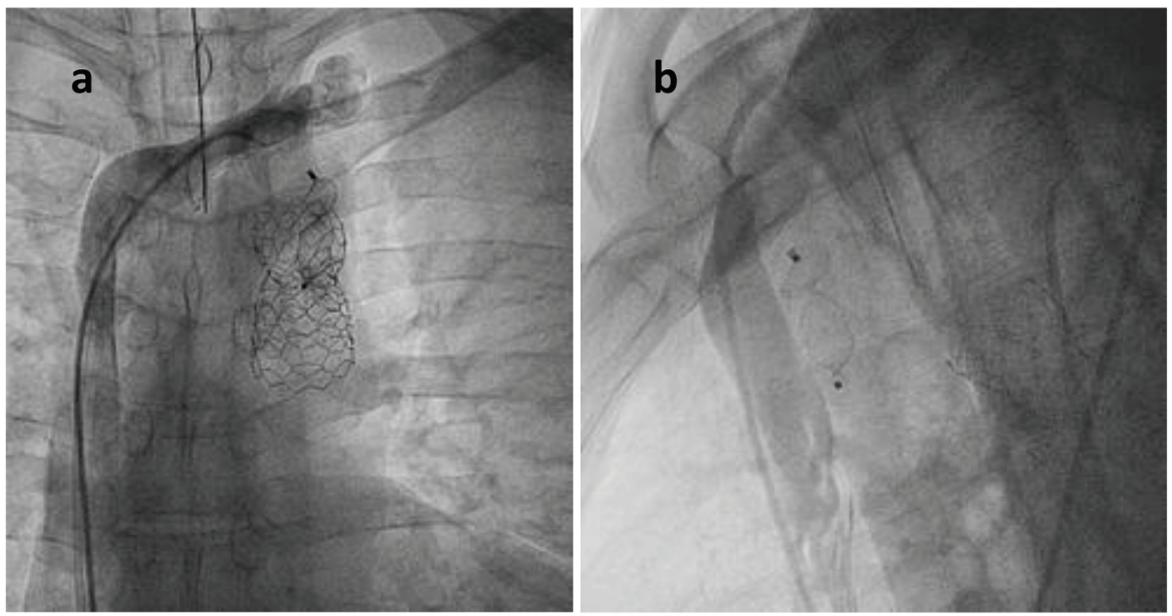

Figure 4. The successful closure of the PLSVC: (a) PA view; (b) lateral view.

\section{Discussion}

In the vast majority of patients, a PLSVC drains via an intact coronary sinus to the right atrium, resulting in normal systemic venous return and no clinical sequelae. However, in $8 \%$ of patients with a PLSVC, the LSVC drains to the left atrium directly, through an unroofed coronary sinus or pulmonary veins $[1,12-17]$.

A hemodynamically significant right-to-left shunt may form. Such a shunt may cause significant systemic desaturation and place the patient at risk for a paradoxical embolic stroke, cerebrovascular accident and intracranial abscess $[10,18,19]$. Surgical repair of the PLSVC may be offered if a patient suffers complications due to a right-to-left shunt. The surgical techniques used to repair a PLSVC are well described, and are specific to the patient's particular anatomical defect [19-23]. More recently successful percutaneous closure of PLSVC using the Amplazter vascular plug device has been reported [4, $10,24]$.

Our patient was unique in the sense that he had two major anomalies that have been undetected for a long time though he was not previously well investigated. He however underwent a coarctation stenting and a percutaneous exclusion of the PLSVC with an Amplatzer vascular plug II successfully.

\section{Conclusion}

The occurrence of the combination of coarctation and PLSVC draining into the left atrium is extremely rare, both carrying significant morbidity and mortality. Our patient had coarctation of the aorta and a PLSVC that was discovered after our evaluation. The PLSVC draining to the left superior pulmonary vein was thought to precipitate transient ischemic stroke and the episode of chest pain through the paradoxical air embolism from a left hand placed cannula. This case highlights that patients with congenital heart defects may suffer from other associated defects. Percutaneous techniques were very successful in treating both anomalies.

\section{References}

1. Geva T, Van Praagh S. Abnormal systemic venous connections. In: Moss AJ, Allen HD, editors. Moss and Adams' Heart Disease in Infants, Children, and Adolescents: Including the Fetus and Young Adult, 7th ed. Philadelphia: Wolters Kluwer Health/ Lippincott Williams \& Wilkins; 2008. pp. 792-803.

2. Bonardi M, Valentini A, Camporotondo R. Unroofed coronary sinus and persistent left superior vena cava: A case report. J Ultrasound. 2012;15(3):179-182.

3. Raghib G, Ruttenberg HD, Anderson RC, Amplatz K, Adams P, Jr., Edwards JE. Termination of Left Superior Vena Cava in Left Atrium, Atrial Septal Defect, and Absence of Coronary Sinus; a Developmental Complex. Circulation. 1965;31:906-918.

4. Zampi JD, Sznycer-Taub NR, Grifka RG. Transcatheter occlusion of a persistent left superior vena cava to the left atrium using the transseptal approach. Catheter Cardiovasc Interv. 2014;83(1):99-103.

5. Cha EM, Khoury GH. Persistent left superior vena cava. Radiologic and clinical significance. Radiology. 1972;103(2):375-381.

6. Meadows WR, Sharp JT. Persistent Left Superior Vena Cava Draining into the Left Atrium without Arterial Oxygen Unsaturation. Am J Cardiol. 1965;16:273-279.

7. Demos TC, Posniak HV, Pierce KL, Olson MC, Muscato M. Venous anomalies of the thorax. AJR Am J Roentgenol. 2004;182(5):1139-1150.

8. Trivedi KR, Freedom RM, Yoo SJ, McCrindle BW, Benson LN. Physiological impact and transcatheter treatment of the persisting left superior caval vein. Cardiol Young. 2002;12(3):218-223.

9. Kim C, Goo HW, Yu JJ, Yun TJ. Coronary sinus ostial atresia with persistent left superior vena cava demonstrated on cardiac $\mathrm{CT}$ in an infant with a functional single ventricle. Pediatr Radiol. 2012;42(6):761-763.

10. Troost E, Gewillig M, Budts W. Percutaneous closure of a persistent left superior vena cava connected to the left 
atrium. Int J Cardiol. 2006;106(3):365-366.

11. Al-Ammouri I, Alhourani A, Innabi A. Late presentation of persistent left superior caval vein in a univentricular heart with successful transcutaneous occlusion using cera lifetech atrial septal occluder. Case Rep Cardiol. 2014;2014:383529.

12. Steinberg I, Dubilier W, Jr., Lukas DS. Persistence of left superior vena cava. Dis Chest. 1953;24(5):479-488.

13. Edwards JE. Malformations of the thoracic veins. In: Gould SE (ed). Pathology of the Heart, 2nd Edition. Springfield, Illinois: Thomas, 1960, pp. 481-496.

14. Lucas RV, Krabil KA. Abnormal systemic venous connections. In: Moss and Adams (eds). Heart Disease in Infants, Children and Adolescents (Volume 1, 5th Edition). Baltimore: Williams and Wilkins, 1995, pp. 874902.

15. Campbell M, Deuchar DC. The left-sided superior vena cava. Br Heart J. 1954;16(4):423-439.

16. Odman P. A persistent left superior vena cava communicating with the left atrium and pulmonary vein. Acta Radiol. 1953;40(6):554-560.

17. Snellen HA, van Ingen HC, Hoefsmit EC. Patterns of anomalous pulmonary venous drainage. Circulation. 1968;38(1):45-63.

18. Butera G, Salvia J, Carminati M. When side matters: contrast echocardiography with injection from the left antecubital vein to detect a persistent left superior vena cava draining to the left atrium in a patient with cerebral stroke. Circulation. 2012;125(1):e1.

19. Vizzardi E, Fracassi F, Farina D, Nardi M, D'Aloia A, Chiari E, Nodari S, et al. Persistence of left superior vena cava, absence of coronary sinus and cerebral ictus. Int J Cardiol. 2008;126(2):e39-41.

20. Shumacker HB, Jr., King H, Waldhausen JA. The persistent left superior vena cava. Surgical implications, with special reference to caval drainage into the left atrium. Ann Surg. 1967;165(5):797-805.

21. van Son JA, Falk V, Mohr FW. Pericardial patch augmentation of restrictive innominate vein and division of left superior vena cava in unroofed coronary sinus syndrome. J Thorac Cardiovasc Surg. 1997;114(1):132-134.

22. Komai H, Naito Y, Fujiwara K. Operative technique for persistent left superior vena cava draining into the left atrium. Ann Thorac Surg. 1996;62(4):1188-1190.

23. Reddy VM, McElhinney DB, Hanley FL. Correction of left superior vena cava draining to the left atrium using extracardiac techniques. Ann Thorac Surg. 1997;63(6):18001802.

24. Recto MR, Sadlo H, Sobczyk WL. Rare case of persistent left superior vena cava to left upper pulmonary vein: pathway for paradoxical embolization and development of transient ischemic attack and subsequent occlusion with an amplatzer vascular plug. J Invasive Cardiol. 2007;19(10):E313-316. 